\title{
Blockade of 12-lipoxygenase expression protects cortical neurons from apoptosis induced by $\beta$-amyloid peptide
}

\author{
A Lebeau', F Terro ${ }^{2}$, W Rostene ${ }^{1}$ and D Pelaprat ${ }^{\star, 1}$ \\ 1 Unité 339 INSERM-UPMC, Hôpital Saint-Antoine, 75571 Paris Cedex 12, France \\ 2 Department of Histology and Cell Biology, Faculty of Medicine, 87025 \\ Limoges, France \\ * Corresponding author: D Pelaprat, Current address: EA 3512, Faculté de \\ Médecine Xavier Bichat, BP 416, 16 rue Henri Huchard, 75870 Paris Cedex \\ 18, France. Tel: + 33-1-44-85-63-10; Fax: + 33-1-40-25-88-34; \\ E-mail: pelaprat@bichat.inserm.fr
}

Received 27.5.03; revised 18.12.03; accepted 19.12.03; published online 23.4.04 Edited by A Finazzi-Agro

\section{Abstract}

The cyclo-oxygenase (COX) and lipoxygenase (LOX) pathways belong to the eicosanoid synthesis pathway, a major component of the chronic inflammatory process occurring in Alzheimer's disease (AD). Clinical studies reported beneficial effects of COX inhibitors, but little is known about the involvement of LOXs in $A D$ pathogenesis. $\beta$-amyloid peptide $(A \beta)$ accumulation contributes to neurodegeneration in $A D$, but mechanisms underlying $A \beta$ toxicity have not been fully elucidated yet. Here, using an antisense oligonucleotide-based strategy, we show that blockade of 12-LOX expression prevents both A $\beta$-induced apoptosis and overexpression of $c-J u n$, a factor required for the apoptotic process, in cortical neurons. Conversely, the 12-LOX metabolite, 12(S)-HETE (12(S)-hydroxy-(5Z, 8Z, 10E, 14Z)eicosatetraenoic acid), promoted c-Jun-dependent apoptosis. Specificity of the 12-LOX involvement was further supported by the observed lack of contribution of 5-LOX in this process. These data indicate that blockade of 12-LOX expression disrupts a c-Jun-dependent apoptosis pathway, and suggest that 12-LOX may represent a new target for the treatment of $A D$.

Cell Death and Differentiation (2004) 11, 875-884.

doi:10.1038/sj.cdd.4401395

Published online 23 April 2004

Keywords: amyloid peptide; lipoxygenases; apoptosis; neurons; Alzheimer's disease; c-Jun; caspases

Abbreviations: $\mathbf{A} \beta, \beta$-amyloid peptide; $\mathrm{AD}$, Alzheimer's disease; $\mathrm{BSO}$, buthionine sulfoximine; COX, cyclo-oxygenase; DAPI, 4',6-diamidino-2-phenylindole; LOX, lipoxygenase; NSAIDs, nonsteroidal anti-inflammatory drugs; 5(S)-HETE, 5(S)-hydroxy-(6E, 8Z, 11Z, 14Z)-eicosatetraenoic acid; 12(S)HETE, 12(S)-hydroxy-(5Z, 8Z, 10E, 14Z)-eicosatetraenoic acid

\section{Introduction}

Alzheimer's disease (AD) involves a chronic CNS inflammatory process that contributes to the neuronal loss and all the pathological features of the disease. ${ }^{1} \mathrm{~A}$ major component of this process is the eicosanoid synthesis pathway, which involves two major routes: the cyclo-oxygenase (COX) and the lipoxygenase (LOX) pathways. ${ }^{2}$ Clinical studies showing that chronic treatment with nonsteroidal anti-inflammatory drugs (NSAIDs) was associated with a delay of $A D$ onset focused attention on the beneficial effect of COX inhibitors. ${ }^{3}$ In contrast, very few studies evaluated the potential interest of LOX inhibitors in the treatment of AD.

One of the main features of $A D$ is the presence of senile plaques in the brain that contain deposits of the 40-42 aminoacid $\beta$-amyloid peptide $(A \beta)$. The central role of $A \beta$ in $A D$ pathogenesis has been well documented. ${ }^{4,5}$ In particular, the rate of accumulation of this peptide correlated with the extent of neurodegeneration. ${ }^{6}$ Furthermore, injection of $A \beta$ aggregates in the rat brain caused neuronal death and behavioral alterations. ${ }^{7,8} \mathrm{~A} \beta$ generated apoptosis in several in vitro models, associated with caspase activation, ${ }^{9-14}$ both of which were also documented in AD brains. ${ }^{15,16}$ Recent data further evidenced a major role of the transcription factor c-Jun in mediating $\mathrm{A} \beta$-induced apoptosis. ${ }^{17-19}$ Overexpression of this factor was detected in neurons surrounding senile plaques. ${ }^{20}$ However, the exact signaling pathways underlying $\mathrm{A} \beta$-induced apoptosis have not been fully elucidated yet.

LOXs incorporate oxygen into specific sites of polyunsaturated fatty acids and are generally classified as 5-, 12- or 15LOXs depending on the site of incorporation. ${ }^{21}$ Both 12- and 5-LOX are expressed in the brain and especially in neurons. $^{22,23}$ LOXs represent important regulators of cell proliferation and death in different cell types. ${ }^{24-26}$ Moreover, a few studies suggested the involvement of 5- or 12-LOX in pathways leading to neuronal death, such as kainic acid excitotoxicity, ${ }^{27}$ apoptosis induced by prion peptide ${ }^{28}$ and oxidative glutamate toxicity. ${ }^{23}$

In this work, we show that blockade of 12-LOX expression protects cortical neurons from $A \beta$-induced apoptosis, through disruption of a c-Jun-dependent apoptosis pathway. These findings suggest that 12-LOX might be considered as a new target for the treatment of $A D$.

\section{Results}

Blockade of 12-LOX expression suppresses $A \beta$-induced apoptosis and reduces $A \beta$-induced caspase activation

12-LOX was previously shown to mediate both oxidative glutamate toxicity and apoptosis induced by buthionine sulfoximine (BSO) in primary cultures of rat cortical neurons, two processes involving glutathione depletion. ${ }^{23}$ Alteration of glutathione metabolism is one of the events triggered by $A \beta^{29}$ and was reported to occur in $A D,{ }^{30}$ which 
suggested that this LOX might also participate in $\mathrm{A} \beta$-induced apoptosis.

Indeed, previous studies using broad-spectrum LOX inhibitors such as nordihydroguaiaretic acid on hippocampal cultures led to equivocal results, reporting either a lack of protection against $\mathrm{A} \beta$-induced apoptosis ${ }^{31}$ or a protective action at high concentrations. ${ }^{32}$ Using more selective inhibitors, we recently suggested a participation of 12-LOX in apoptosis triggered by $\mathrm{A} \beta$ in cortical neurons. ${ }^{33}$ However, inhibitors can only provide circumstantial evidence about the role of LOXs in A $\beta$-induced toxicity, since most of these compounds also possess other characteristics such as proor antioxidant properties, ${ }^{25,26,34-36}$ which might lead to LOX-independent effects. In order to assess the protective potential of 12-LOX blockade towards A $\beta$-induced apoptosis, we used here an antisense oligonucleotide-based strategy.

When extracts of cortical cells were probed with an antibody raised against murine leukocyte 12-LOX, two bands $(75-78 \mathrm{kDa})$ were detected in Western blot experiments (Figure 1a). A similar doublet pattern was already observed in previous studies on these cultures. ${ }^{23}$ As shown in Figure 1a, pretreatment of cortical cells for $48 \mathrm{~h}$ with the antisense 12-LOX oligonucleotide induced an important decrease in the expression of 12-LOX protein. When normalized to corresponding actin levels, the effect of the oligonucleotide represented an $85 \%$ decrease in 12-LOX protein levels.

As illustrated in Figure 1b, a 24-h treatment of cortical cells with $25 \mu \mathrm{M} \mathrm{A} \beta_{25-35}$ increased the percentage of apoptotic cells, as assessed by $4^{\prime}, 6$-diamidino-2-phenylindole (DAPI) staining. This proapoptotic effect of $A \beta$ was totally suppressed by a 48-h pretreatment of the cells with the 12-LOX antisense oligonucleotide, whereas the sense or the scramble 12-LOX oligonucleotide did not show any protective action (Figure 1b). Similar results were obtained when apoptosis was assessed by TUNEL experiments (Figure 1c).

Numerous studies indicated that $A \beta$-induced cell death was associated with the activation of the caspase cascade. ${ }^{10-14}$ We therefore investigated the effect of 12-LOX downregulation on $\mathrm{A} \beta$-induced caspase activation. As shown in Figure 2, treatment of cortical cells with $25 \mu \mathrm{M} \mathrm{A} \beta$ led to the activation of caspase-2, -3 and -8. Pretreatment with the 12-LOX antisense oligonucleotide strongly inhibited $\mathrm{A} \beta$-induced activation of all three caspases (Figures $2 \mathrm{a}-\mathrm{c}$ ). The oligonucleotide effect represented $67 \pm 4,68 \pm 4$ and $78 \pm 2 \%$ ( $n=3$ independent experiments) decreases in the $\mathrm{A} \beta$-induced activation of caspase-2, -3 and -8 , respectively. No alteration of the $A \beta$-induced caspase activation was observed upon treatment with the 12-LOX sense oligonucleotide (Figures 2d-f).

The protection against $\mathrm{A} \beta$-induced apoptosis afforded by 12-LOX blockade further suggested a proapoptotic involvement of 12 -LOX in cortical neurons. Previous studies ${ }^{23,37}$ indicated that the 12-LOX isoform present in primary cultures of rat cortical neurons was the 12-LOX cloned from rat brain, ${ }^{38}$ belonging to the family of leukocyte-type 12-LOXs. Like other members of this family, rat brain 12-LOX presented high similarity with 15-LOX. However, a striking characteristic of this isoform was that it generated predominantly $12(S)$ - a
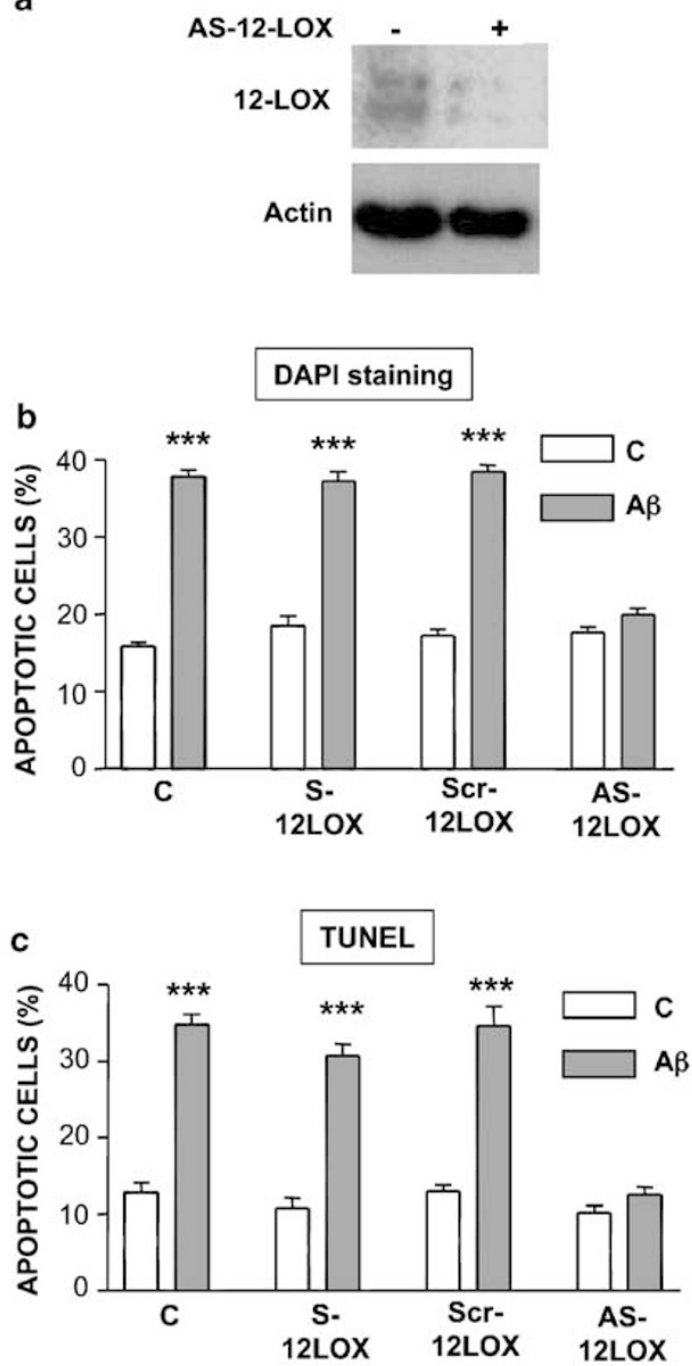

Figure 1 Downregulation of 12-LOX expression by antisense oligonucleotide prevents $\mathrm{A} \beta$-induced apoptosis in cortical neurons. (a) Cell lysates $(25 \mu \mathrm{g}$ protein/lane) from untreated cortical cultures or cultures treated for $48 \mathrm{~h}$ with 12 LOX antisense oligonucleotide (AS-12-LOX, $4 \mu \mathrm{M}$ ) were resolved in $4-20 \%$ SDS-polyacrylamide gel gradients and transferred to PVDF membranes. Membranes were probed with anti-12-LOX antibody, stripped and reprobed with anti-actin antibody as described in Materials and methods. (b and $\mathbf{c}$ ) Cortical neurons in primary culture were treated for $48 \mathrm{~h}$ with 12-LOX antisense oligonucleotide (AS-12-LOX, $4 \mu \mathrm{M}$ ), sense oligonucleotide (S-12-LOX, $4 \mu \mathrm{M}$ ) or scramble oligonucleotide (Scr-12-LOX, $4 \mu \mathrm{M}$ ) and then with (black bars) or without (white bars) $25 \mu \mathrm{M} \mathrm{A} \beta_{25-35}$ for an additional 24-h period. The percentage of apoptotic cells was evaluated by DAPI staining (b) or TUNEL labeling (c) as described in Materials and methods. Results represent means \pm S.E.M. $(n=6-$ 12 culture wells) obtained in one typical experiment. ${ }^{* * *} P<0.001$ versus corresponding control without $A \beta_{25-35}$ (one-way ANOVA followed by NewmanKeuls test)

hydroxy-(5Z, 8Z, 10E, 14Z)-eicosatetraenoic acid (12(S)-HETE), with only small amounts of $15(S)$-HETE. ${ }^{38,39}$

We therefore evaluated whether exogenous 12(S)-HETE could induce apoptosis in cortical cells. As illustrated in Figure 3 , a concentration-dependent increase in the percentage of apoptotic cells was observed following a 24-h treatment of the cultures with 12(S)-HETE. 

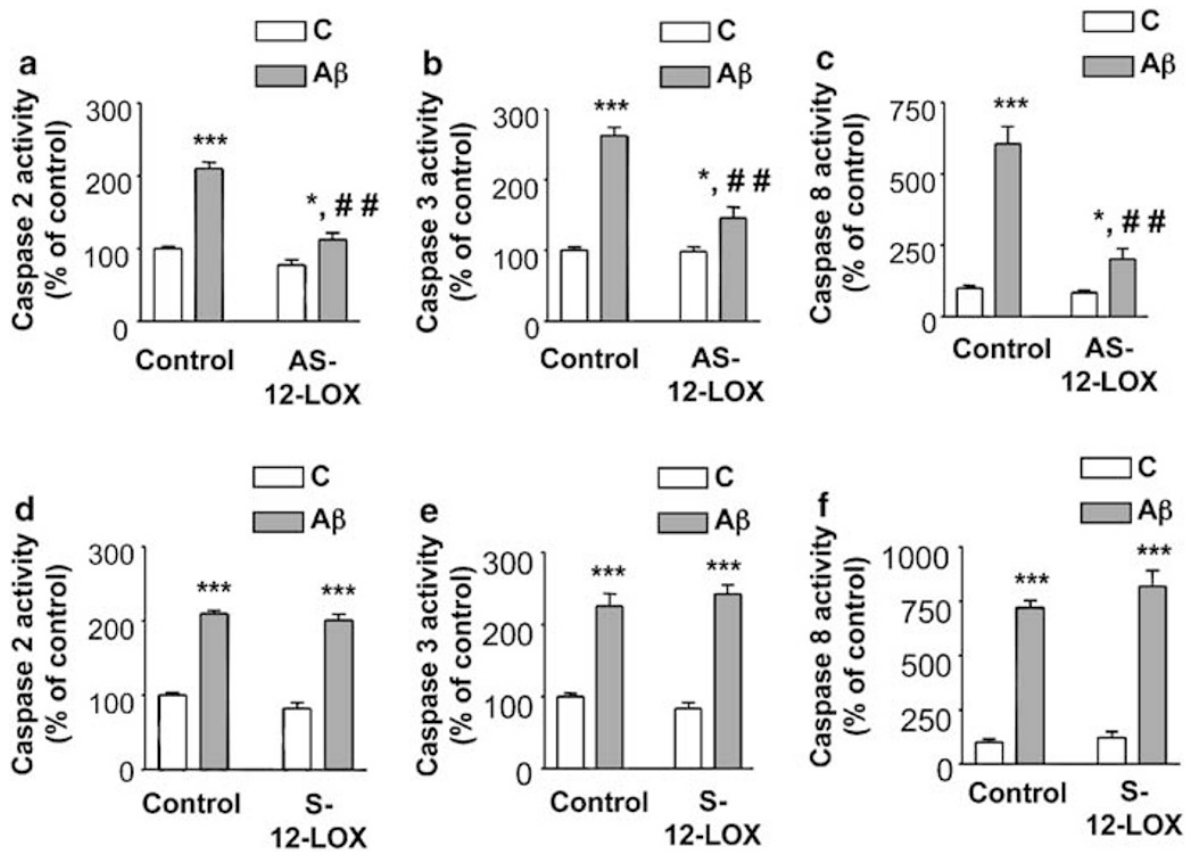

Figure 2 Downregulation of 12-LOX expression by antisense oligonucleotide decreases A $\beta$-induced caspase activation in cortical neurons. Cortical neurons in primary culture were treated for $48 \mathrm{~h}$ with 12-LOX antisense oligonucleotide (a-c: AS-12-LOX, $4 \mu \mathrm{M}$ ) or sense oligonucleotide (d-f: S-12-LOX, $4 \mu \mathrm{M}$ ) and then with (black bars) or without (white bars) $25 \mu \mathrm{M} \mathrm{A} \beta_{25-35}$ for an additional 24-h period. Activity of caspase-2 (a, d), $-3(\mathbf{b}, \mathbf{e})$ and -8 (c, f) were assessed by a fluorimetric assay using the fluorogenic substrates Ac-VDVAD-AMC, Ac-DEVD-AMC and Ac-IEPD-AMC, respectively. Results represent means \pm S.E.M. ( $n=6-12$ culture wells) obtained in one typical experiment. ${ }^{* \star *} P<0.001$ versus corresponding control without $\mathrm{A} \beta_{25-35} ;{ }^{*} P<0.05$ versus corresponding control without $\mathrm{A} \beta_{25-35}$, ${ }^{* \#} P<0.01$ versus $\mathrm{A} \beta_{25-35}$ alone (one-way ANOVA followed by Newman-Keuls test)

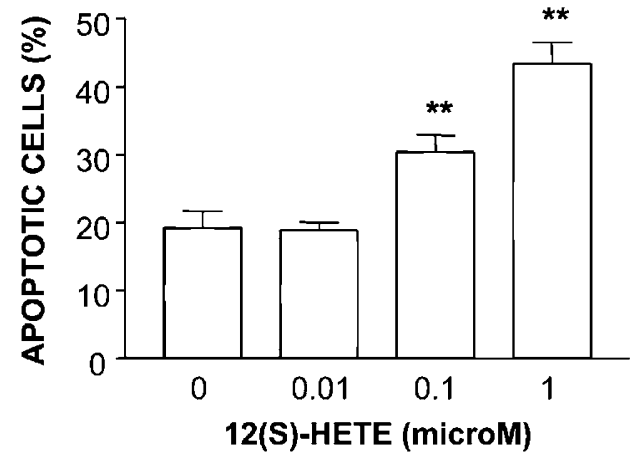

Figure 3 12-LOX metabolite, 12(S)-HETE, induces apoptosis in cortical neurons. Cortical neurons in primary culture were treated for $24 \mathrm{~h}$ with increasing concentrations of $12(S)$-HETE. The percentage of apoptotic cells was evaluated by DAPI staining as described in Materials and methods. Results represent means \pm S.E.M. ( $n=6$ culture wells) obtained in one typical experiment ${ }^{* *} P<0.01$ versus control without $12(S)$-HETE (one-way ANOVA followed by Dunnett's test)

\section{Blockade of 5-LOX expression does not alter A $\beta$-induced apoptosis}

Previous studies indicated that 5-LOX could play a critical role in neuronal cell death, mediating, for instance, kainic acidinduced excitotoxicity ${ }^{27}$ and apoptosis generated by prion peptide. ${ }^{28}$ We recently reported that the 5 -LOX inhibitor, caffeic acid, did not counteract apoptosis induced by $A \beta$ in cortical neurons, suggesting that 5-LOX was not involved in this degeneration process. ${ }^{33}$ In the present study, we further evaluated this hypothesis through the same strategy as that used for 12-LOX.

As shown in Figure 4a, pretreatment of cortical cells for $48 \mathrm{~h}$ with the antisense 5-LOX oligonucleotide induced an important decrease in the expression of the 5-LOX protein. When normalized to corresponding actin levels, the effect of the oligonucleotide represented a $75 \%$ decrease in 5 -LOX protein levels.

However, at variance with what was observed above for $12-$ LOX, such a pretreatment with the 5-LOX antisense oligonucleotide did not counteract the proapoptotic effect of $\mathrm{A} \beta$ (Figure 4b). Similarly, no effect was observed with the corresponding sense oligonucleotide (Figure $4 b$ ).

We also evaluated whether the 5-LOX metabolite, 5(S)hydroxy-(6E, 8Z, 11Z, 14Z)-eicosatetraenoic acid (5(S)HETE), could induce apoptosis in cortical cells. Contrasting with what was obtained above with 12(S)-HETE, no increase in the percentage of apoptotic cells was observed following a 24-h treatment of the cultures with 5(S)-HETE concentrations up to $1 \mu \mathrm{M}$ (Figure $4 \mathrm{c}$ ).

\section{Blockade of 12-LOX expression disrupts a c-Jun-dependent $\mathbf{A} \beta$-induced apoptotic pathway}

Several studies revealed that the transcription factor c-Jun represented a common mediator in neuronal apoptosis triggered by several stimuli, such as growth factor deprivation, oxidative stress or excitotoxicity. ${ }^{40-42}$ Moreover, both c-Jun expression and activation were found to be increased following exposure of neurons to $\mathrm{A} \beta$, and recent data suggested a 

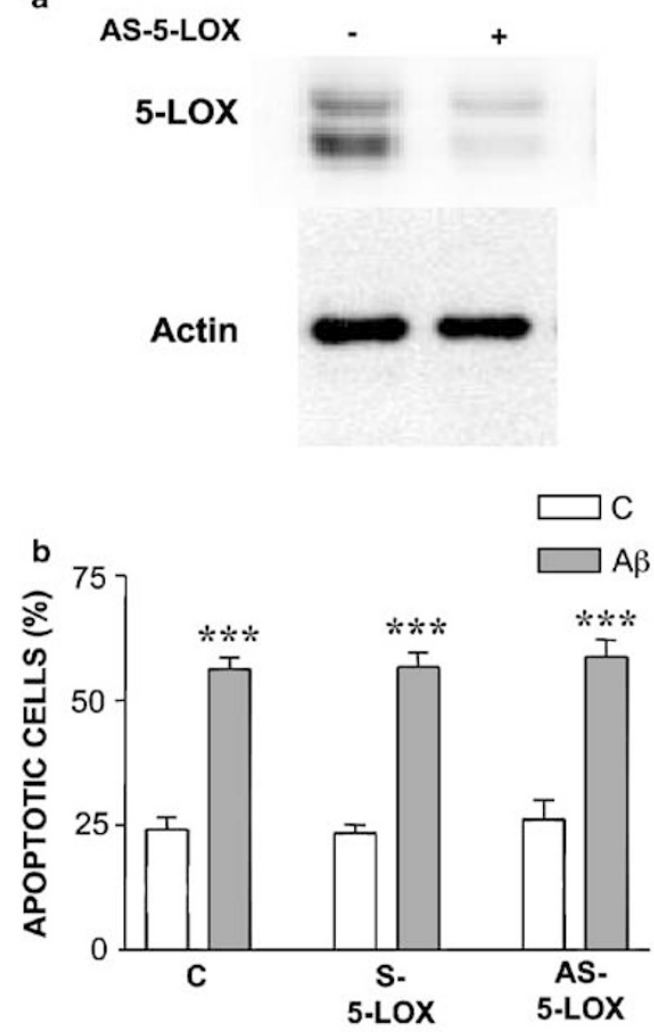

c

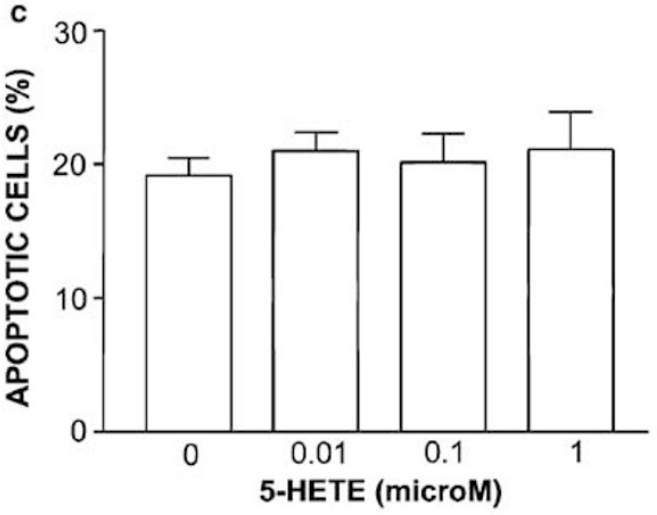

Figure 4 Downregulation of 5-LOX expression does not counteract $A \beta$-induced apoptosis, and $5(S)$-HETE does not induce apoptosis in cortical neurons. (a) Cell lysates ( $25 \mu \mathrm{g}$ protein/lane) from untreated cortical cultures or cultures treated for $48 \mathrm{~h}$ with 5-LOX antisense oligonucleotide (AS-5-LOX, $4 \mu \mathrm{M}$ ) were resolved in 4-20\% SDS-polyacrylamide gel gradients and transferred to PVDF membranes. Membranes were probed with anti-5-LOX antibody, stripped and reprobed with anti-actin antibody as described in Materials and methods. (b) Cortical neurons in primary culture were treated for $48 \mathrm{~h}$ with 5-LOX antisense oligonucleotide (AS-5-LOX, $4 \mu \mathrm{M}$ ) or sense oligonucleotide (S-5-LOX, $4 \mu \mathrm{M}$ ) and then with (black bars) or without (white bars) $25 \mu \mathrm{M} \mathrm{A} \beta_{25-35}$ for an additional 24-h period. The percentage of apoptotic cells was evaluated by DAPI staining as described in Materials and methods. Results represent means +S.E.M. ( $n=6-12$ culture wells) obtained in one typical experiment. ${ }^{* * \star} P<0.001$ versus corresponding control without $\mathrm{A} \beta_{25-35}$ (one-way ANOVA followed by NewmanKeuls test). (c) Cortical neurons in primary culture were treated for $24 \mathrm{~h}$ with increasing concentrations of 5(S)-HETE. The percentage of apoptotic cells was evaluated by DAPI staining as described in Materials and methods. Results represent means \pm S.E.M. ( $n=6$ culture wells) obtained in one typical experiment critical role of this transcription factor in $\mathrm{A} \beta$-induced apoptosis. ${ }^{17-19,43,44}$ We therefore investigated whether 12-LOX blockade could interfere with such an $\mathrm{A} \beta$-induced c-Jundependent apoptotic pathway in cortical cells.

We first examined the effect of 12-LOX antisense oligonucleotide on $\mathrm{A} \beta$-induced increase in $\mathrm{C}$-Jun expression. In agreement with our previous observations, ${ }^{33}$ treatment of the cultures with $25 \mu \mathrm{M} \mathrm{A} \beta$ induced an increase in the percentage of c-Jun-positive neurons (Figure 5). A 48-h pretreatment with the 12-LOX antisense oligonucleotide suppressed this effect, suggesting that 12-LOX mediated the increase in c-Jun expression induced by $\mathrm{A} \beta$ (Figure 5 ). No alteration of the $\mathrm{A} \beta$-induced increase in the percentage of c-Jun-positive neurons was observed upon treatment with the sense 12LOX oligonucleotide (Figure 5).

We then determined whether c-Jun was involved in $A \beta$ induced apoptosis under our experimental conditions. Pretreatment with a c-Jun antisense oligonucleotide decreased the expression of $c$-Jun protein as observed in Western blot experiments (Figure 6a). When normalized to corresponding actin levels, the oligonucleotide effect represented a $60 \%$ decrease in the amount of c-Jun protein. As illustrated in Figure $6 b$, pretreatment of cortical cells with the c-Jun antisense oligonucleotide, but not with the sense oligonucleotide, inhibited apoptosis induced by $\mathrm{A} \beta$. The effect of the $\mathrm{c}$-Jun antisense oligonucleotide represented a $75 \%$ decrease in $\mathrm{A} \beta$ induced apoptosis. Similar results were obtained when apoptosis was assessed by TUNEL experiments (Figure 6c). Consistent with previous data showing a protective action of dominant-negative mutants of c-Jun in this experimental system, ${ }^{18}$ these results indicated that c-Jun was involved in the death process triggered by $A \beta$ in cortical cells.

Recent data suggested that the downstream components of the c-Jun-dependent apoptosis pathway induced by $\mathrm{A} \beta$ included induction of Fas ligand expression and caspase-8

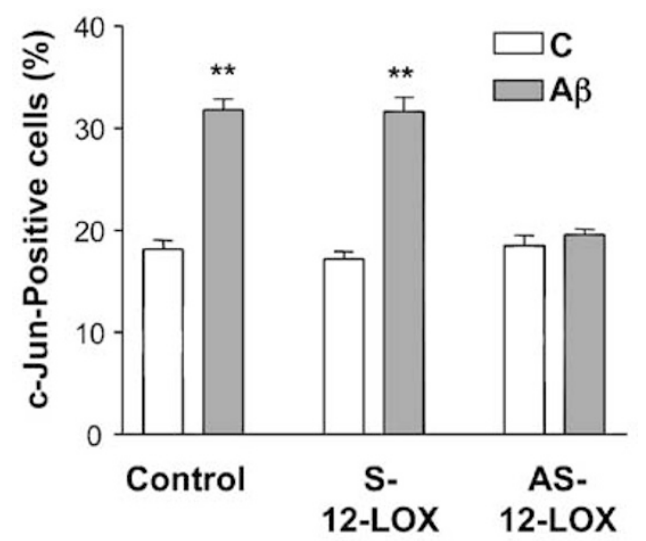

Figure 5 12-LOX antisense oligonucleotide suppresses the increase in the percentage of $c$-Jun-positive cells induced by $A \beta$ in cortical neurons. Cortical neurons in primary culture were treated for $48 \mathrm{~h}$ with 12-LOX antisense oligonucleotide (AS-12-LOX, $4 \mu \mathrm{M}$ ) or sense oligonucleotide (S-12-LOX, $4 \mu \mathrm{M}$ ) and then with (black bars) or without (white bars) $25 \mu \mathrm{M} \mathrm{A} \beta_{25-35}$ for an additional 24-h period. The percentage of c-Jun-positive cells was evaluated by immunocytochemistry as described in Materials and methods. Results represent means \pm S.E.M. ( $n=6$ culture wells) obtained in one typical experiment. ${ }^{\star \star} P<0.01$ versus corresponding control without $A \beta_{25-35}$ (one-way ANOVA followed by Newman-Keuls test) 


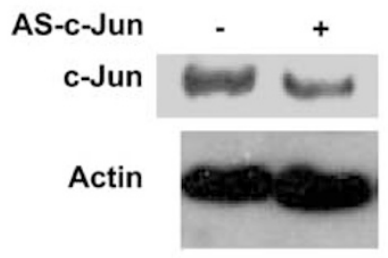

DAPI staining

b
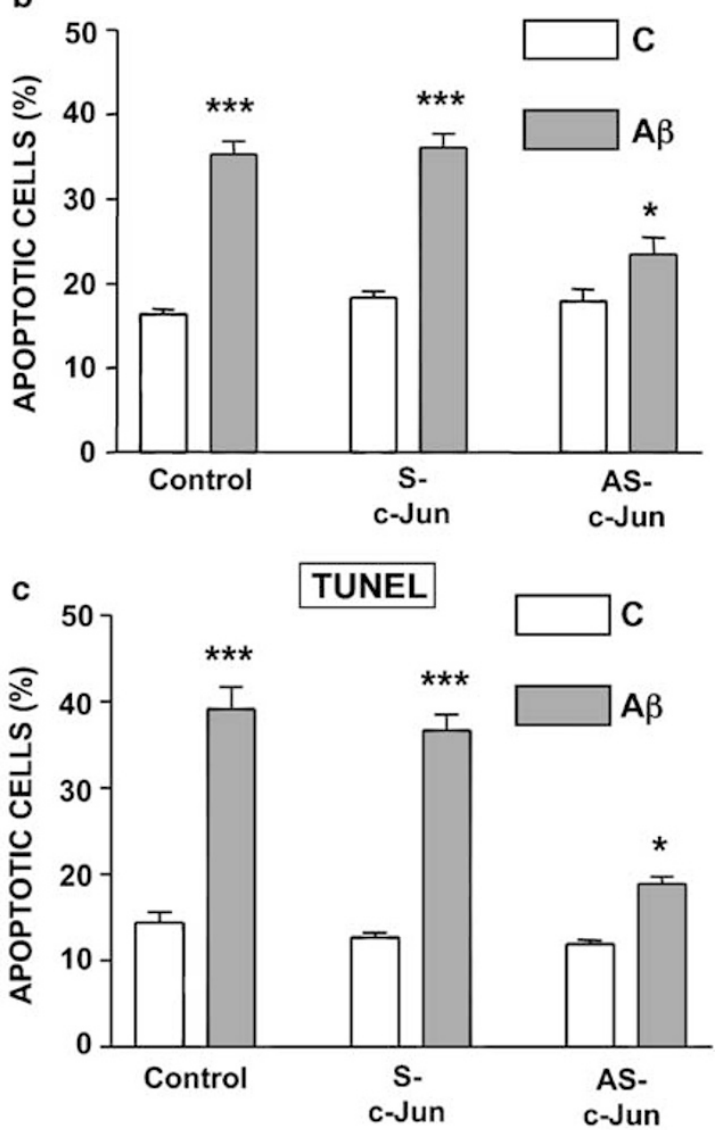

Figure 6 Downregulation of c-Jun expression by c-Jun antisense oligonucleotide prevents $\mathrm{A} \beta$-induced apoptosis in cortical neurons. (a) Cell lysates $(25 \mu \mathrm{g}$ protein/lane) from untreated cortical cultures or cultures treated for $48 \mathrm{~h}$ with c-Jun antisense oligonucleotide (AS-c-Jun, $4 \mu \mathrm{M}$ ) were resolved in 4-20\% SDSpolyacrylamide gel gradients and transferred to PVDF membranes. Membranes were probed with anti-c-Jun antibody, stripped and reprobed with anti-actin antibody as described in Materials and methods. (b and c) Cortical neurons in primary culture were treated for $48 \mathrm{~h}$ with c-Jun antisense oligonucleotide (AS-cJun, $4 \mu \mathrm{M}$ ) or sense oligonucleotide (S-c-Jun, $4 \mu \mathrm{M}$ ) and then with (black bars) or without (white bars) $25 \mu \mathrm{M} \mathrm{A} \beta_{25-35}$ for an additional 24-h period. The percentage of apoptotic cells was evaluated by DAPI staining (b) or TUNEL labeling (c) as described in Materials and methods. Results represent means \pm S.E.M. $(n=$ 6-12 culture wells) obtained in one typical experiment. ${ }^{* * *} P<0.01$ versus corresponding control without $\mathrm{A} \beta_{25-35} ;{ }^{*} P<0.05$ versus corresponding control without $\mathrm{A} \beta_{25-35}$ (one-way ANOVA followed by Newman-Keuls test)

activation. ${ }^{18}$ However, nothing had been reported yet on the consequences of $\mathrm{c}$-Jun downregulation on $\mathrm{A} \beta$-induced caspase activation. We therefore investigated the effect of c-Jun antisense oligonucleotide on caspase activities triggered by $\mathrm{A} \beta$ in our experimental model. As illustrated in
Figure 7c, pretreatment of cortical cultures with c-Jun antisense oligonucleotide decreased the $A \beta$-induced activation of caspase 8 . In contrast, no alteration of the $A \beta$-induced activation of caspase- 2 and -3 was observed (Figures $7 a$ and b). Treatment with the c-Jun sense oligonucleotide did not alter $\mathrm{A} \beta$-induced activation of caspase-2, -3 and -8 (Figures $7 d-f)$. These data indicated an involvement of $c-J u n$ in the activation of caspase- 8 triggered by $\mathrm{A} \beta$.

Taken together, our findings indicated both an involvement of 12 -LOX in the $A \beta$-mediated induction of $c$-Jun and a participation of this transcription factor in the apoptotic process, suggesting that 12-LOX lay upstream of c-Jun in the $\mathrm{A} \beta$-induced apoptotic pathway. The ability of 12 -LOX to trigger a c-Jun-dependent apoptotic pathway was further investigated by evaluating the role of c-Jun in apoptosis induced by $12(S)$-HETE.

As presented in Figure 8a, a 24-h treatment of cortical cells with 12(S)-HETE induced a concentration-dependent increase in the percentage of c-Jun-positive neurons, which strikingly paralleled the proapoptotic action of this compound (Figure 3). Furthermore, pretreatment with the c-Jun antisense oligonucleotide totally protected cortical cells from apoptosis induced by $12(S)$-HETE, whereas no protection was observed following treatment with the corresponding sense oligonucleotide (Figure $8 \mathrm{~b}$ ). These data indicated that the 12-LOX metabolite, 12(S)-HETE, induced a c-Jundependent apoptotic pathway in cortical neurons.

\section{Discussion}

In the present report, we demonstrated that downregulation of 12-LOX suppressed apoptosis, strongly decreased the activation of caspase-2, -3 and -8 and prevented c-Jun overexpression induced by $\mathrm{A} \beta$ in rat cortical neurons. The requirement of $c$-Jun for the death process induced by $A \beta$ in these cells was further indicated by the prevention of both $A \beta$ induced apoptosis and caspase-8 activation following pretreatment with a c-Jun antisense oligonucleotide. Moreover, we showed that the 12-LOX metabolite 12(S)-HETE induced apoptosis, associated with an increase in C-Jun expression and suppressed by a c-Jun antisense oligonucleotide. These data suggest that blockade of 12-LOX expression protects cortical neurons from $\mathrm{A} \beta$-induced apoptosis, through disruption of a c-Jun-dependent apoptosis pathway. The specificity of involvement of 12-LOX in this process was further supported by both the lack of protection observed following downregulation of 5-LOX expression and the lack of toxicity of the 5-LOX metabolite, 5(S)-HETE, in this experimental model.

It has been reported that LOXs play an important role in neuronal metabolism and function. ${ }^{45}$ Indeed, LOX metabolites were found to be synthesized in both neurons and glial cells. ${ }^{21,46-48}$ Some of them, such as 5- and 12-hydroxyeicosatetraenoic acids, have been reported to exert various actions on neurons, including modulation of $\mathrm{Na}-\mathrm{K}$ ATPase activity, ${ }^{49}$ neurotransmitter release ${ }^{50}$ or alteration of membrane potential. ${ }^{51,52}$ LOXs also act as regulators of cell proliferation and death, and have been implied in the mediation of apoptosis induced by various physical or chemical agents such as UV light, oxidative stress or receptor ligands 

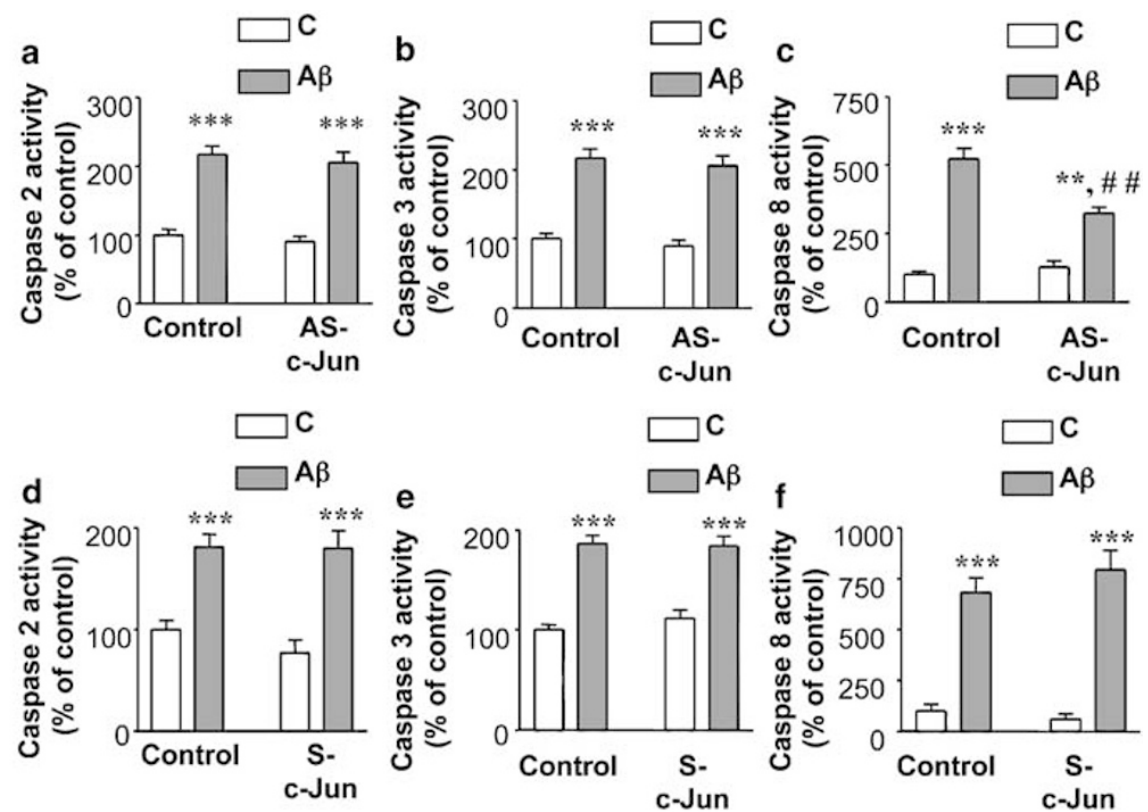

Figure 7 c-Jun antisense oligonucleotide decreases caspase-8 activation in cortical neurons. Cortical neurons in primary culture were treated for $48 \mathrm{~h}$ with c-Jun antisense oligonucleotide (a-c: AS-c-Jun, $4 \mu \mathrm{M}$ ) or sense oligonucleotide (d-f: S-c-Jun, $4 \mu \mathrm{M}$ ) and then with (black bars) or without (white bars) $25 \mu \mathrm{M} \mathrm{A} \beta_{25-35}$ for an additional 24-h period. Activity of caspase-2 (a, d), $-3(\mathbf{b}, \mathbf{e})$ and $-8(\mathbf{c}, \mathbf{f})$ were assessed by a fluorimetric assay using the fluorogenic substrates Ac-VDVAD-AMC, AcDEVD-AMC and Ac-IEPD-AMC, respectively. Results represent means \pm S.E.M. ( $n=6-12$ culture wells) obtained in one typical experiment. ${ }^{* *}$ or ${ }^{* \star} P<0.001$ or $<0.01$ versus corresponding control without $\mathrm{A} \beta_{25-35}$; ${ }^{\# \#} \mathrm{P}<0.01$ versus $\mathrm{A} \beta_{25-35}$ alone (one-way ANOVA followed by Newman-Keuls test)

such as TNF $\alpha$ or Fas ligand, in different types of cells of peripheral origin. ${ }^{25,26}$

In contrast, only a small number of studies investigated the involvement of LOXs in the various signaling pathways leading to neurodegeneration. However, data obtained thus far suggest a crucial participation of these enzymes in several of these pathways. For instance, 5-LOX was shown to mediate kainic acid-induced excitotoxicity ${ }^{27}$ and apoptosis generated by prion peptide. ${ }^{28}$ With regard to 12 -LOX, this enzyme was previously shown to mediate both oxidative glutamate toxicity and BSO-induced apoptosis. ${ }^{23}$ In a recent study, ${ }^{33}$ we showed that baicalein, a 12-LOX inhibitor, protected cortical neurons from $A \beta$-induced apoptosis, suggesting a role for 12 -LOX in the apoptotic process triggered by $\mathrm{A} \beta$ in these cells.

The present results indicate that downregulation of 12-LOX expression by an antisense oligonucleotide leads to the suppression of $A \beta$-induced apoptosis. When combining these data to those previously obtained with the 12-LOX inhibitor, it thus appears that protection against neuronal death induced by $\mathrm{A} \beta$ could be achieved upon blockade of 12-LOX through either inhibition of the enzyme or downregulation of its expression. Moreover, it is now well documented that caspases participate in $A \beta$-induced apoptosis, ${ }^{10-13}$ and that their activation correlates with apoptotic features in $A D$ brains. ${ }^{53,54}$ In particular, caspase-2, -3 and -8 have been reported to be activated in neurons following $\mathrm{A} \beta$ treatment. $^{10-}$ $12,14,18$ We show here that the protective action of 12-LOX antisense oligonucleotide against $\mathrm{A} \beta$-mediated apoptosis is associated with decreases in the activation of these caspases. Taken together, these data indicate that 12-LOX blockade counteracts the apoptotic process triggered by $\mathrm{A} \beta$ in cortical cells.
Both pro- and antiapoptotic roles of LOXs have been reported in various cell types. ${ }^{25,26}$ However, the protection afforded by 12 -LOX blockade against $A \beta$-induced apoptosis as well as the induction of apoptosis by $12(S)$-HETE observed in the present work favored a proapoptotic involvement of this enzyme in cortical cells. These findings add to previous studies showing that 12-LOX mediated apoptosis induced by other stimuli, such as glutamate or $\mathrm{BSO},{ }^{23}$ and suggest that this LOX might represent a common intermediate in neurodegenerative processes triggered by various insults.

In the present study, we also demonstrated both a lack of protection of cortical neurons by pretreatment with a 5-LOX antisense oligonucleotide and a lack of toxicity of the 5-LOX metabolite, 5(S)-HETE. These findings add to our previous observations showing that the 5-LOX inhibitor, caffeic acid, did not counteract $\mathrm{A} \beta$-induced apoptosis in this experimental system. ${ }^{33}$ Taken together, these data suggest that 5-LOX does not participate in the apoptotic process induced by $A \beta$ in cortical neurons, representing an important support to the specificity of the role of 12-LOX pathway in this process.

It should be stressed, however, that these results do not rule out the possibility of a participation of 5-LOX in the pathology of $A D$, since this pathology most probably encompasses several other parameters, which are not present in this in vitro model. In this respect, it is interesting to note that a relationship between 5-LOX promoter polymorphism and $A D$ onset was recently reported. ${ }^{55}$

One of the typical feature found in post-mortem studies on brains from $A D$ patients is an overexpression of c-Jun, ${ }^{56}$ which is also a hallmark of $A \beta$-induced apoptosis in neuronal cultures. ${ }^{17,44}$ This transcription factor was found to play a major role in $A \beta$-induced neurotoxicity. ${ }^{17,18}$ In the present 

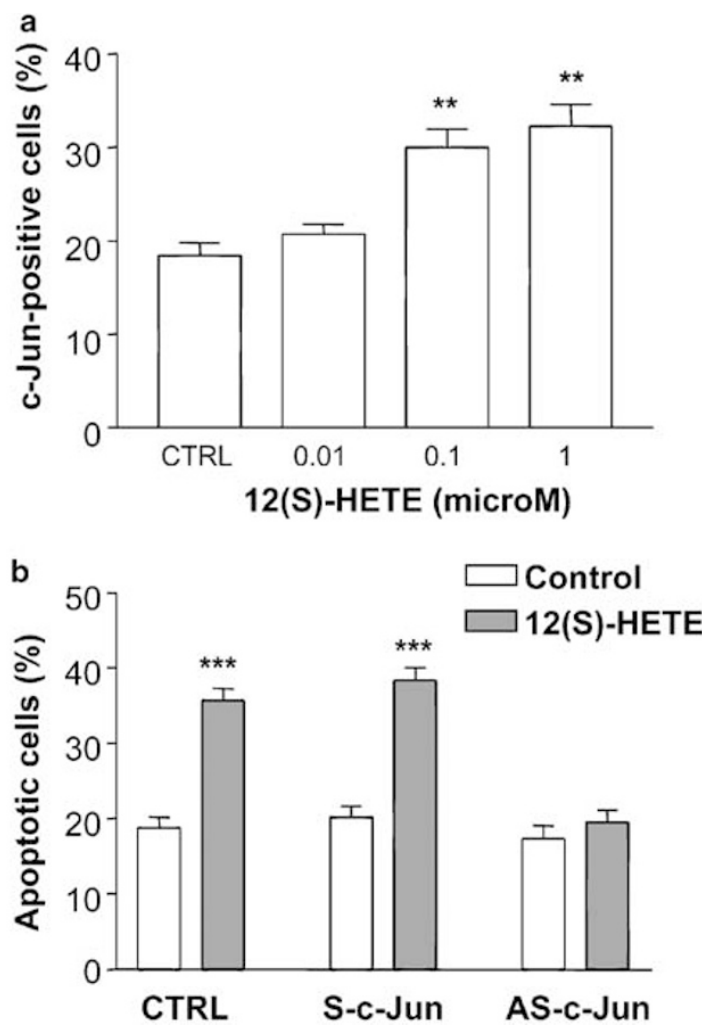

Figure 8 12-LOX metabolite, 12(S)-HETE, induces a c-Jun-dependent apoptosis pathway in cortical neurons. (a) Cortical neurons in primary culture were treated for $24 \mathrm{~h}$ with $12(\mathrm{~S})$-HETE. The percentage of c-Jun-positive cells was evaluated by immunocytochemistry as described in Materials and methods. Results represent means \pm S.E.M. ( $n=6$ culture wells) obtained in one typical experiment. ${ }^{* *} P<0.01$ versus control without $12(S)$-HETE (one-way ANOVA followed by Dunnett's test). (b) Cortical neurons in primary culture were treated for $48 \mathrm{~h}$ with c-Jun antisense oligonucleotide (AS-c-Jun, $4 \mu \mathrm{M}$ ) or sense oligonucleotide (S-c-Jun, $4 \mu \mathrm{M}$ ) and then with (black bars) or without (white bars) $1 \mu \mathrm{M} 12(S)$-HETE for an additional 24-h period. The percentage of apoptotic cells was evaluated by DAPI staining as described in Materials and Methods. Results represent means \pm S.E.M. $(n=6-12$ culture wells) obtained in one typical experiment. ${ }^{* *} P<0.01$ versus corresponding control without 12(S)-HETE (oneway ANOVA followed by Newman-Keuls test)

study, we showed that the protective action of 12-LOX antisense oligonucleotide against $\mathrm{A} \beta$-mediated toxicity was associated with the suppression of $c$-Jun overexpression. Furthermore, pretreatment with a c-Jun antisense oligonucleotide protected cortical neurons from $\mathrm{A} \beta$-induced apoptosis and decreased the activation of caspase-8, indicating that this transcription factor was involved in the death process induced by $\mathrm{A} \beta$ under our experimental conditions. The data obtained with the c-Jun antisense oligonucleotide corroborate previous studies performed on cortical cultures, showing that dominant-negative mutants of $c$-Jun afforded protection against $A \beta$-induced apoptosis. ${ }^{18}$

These findings suggested that 12-LOX was positioned upstream of c-Jun in the apoptotic pathway induced by $\mathrm{A} \beta$. They also suggested that this enzyme could represent a critical step in the triggering of a c-Jun-dependent apoptosis pathway. This hypothesis was further supported by our observation that the 12-LOX metabolite, 12(S)-HETE, induced a c-Jun-dependent death process. Interestingly, although such an involvement of 12-LOX in the induction of c-Jun-dependent apoptosis had not been previously evidenced, it lies in accordance with some data from literature since BSOinduced apoptosis, shown to be mediated by $12-\mathrm{LOX},{ }^{23}$ was also reported to be c-Jun dependent. ${ }^{57}$

The relationship between $\mathrm{c}$-Jun and $\mathrm{A} \beta$-induced activation of caspases has not been fully elucidated yet. The activation of caspase-8 upon $\mathrm{A} \beta$ treatment of cortical neurons was recently suggested to occur through a c-Jun-mediated induction of Fas ligand. ${ }^{18}$ Our observation that $A \beta$-induced caspase- 8 activation is prevented by a c-Jun antisense oligonucleotide provides evidence for an involvement of this factor in the activation of caspase-8. Interestingly, the lack of effect of the c-Jun antisense oligonucleotide on caspase-2 and -3 activations lies, in contrast, with the previously reported inhibition of these caspases upon treatment with CEP-1347, an inhibitor of the c-Jun N-terminal kinase (JNK). ${ }^{19,58}$ It could thus be postulated that the effect of CEP-1347 on these two caspases reflected disruption of the JNK action on a target different from c-Jun, such as activating transcription factor 2 or Elk1. ${ }^{59}$

It should also be noticed that, despite its lack of effect on the activation of caspase- 2 and -3 , the c-Jun antisense oligonucleotide afforded protection of cortical neurons against $\mathrm{A} \beta$-induced apoptosis. Whereas the involvement of caspase-3 in $\mathrm{A} \beta$-induced neuronal apoptosis still remains controversial, ${ }^{10,13,60}$ caspase-8 activation ${ }^{11}$ and caspase-2 activation $^{12,61}$ were separately identified as necessary steps for $\mathrm{A} \beta$-induced neuronal death. Our results support the hypothesis that the induction of these two caspases is needed for completion of the apoptotic process.

The involvement of $c$-Jun in the $A \beta$-induced activation of caspase- 8 further suggests the existence of a causal link between the suppression of c-Jun induction and the decrease in caspase-8 activation observed following 12-LOX downregulation. However, the decreased activation of caspase-2 and -3 , also obtained under those experimental conditions, cannot be explained by the sole disruption of c-Jun induction and would thus imply additional mechanisms. For instance, as mentioned above for the action of CEP-1347, the effect of 12 LOX downregulation on these two caspases could involve decreased activation of other targets of the JNK signaling pathway.

The beneficial effects of NSAIDs in AD focused attention on the therapeutic interest of COX inhibitors. ${ }^{3}$ However, the present study suggests that the 12-LOX pathway could also play an important role in this pathology. Indeed, the 12-LOX inhibitor baicalein is the main component of an herbal medicine (Sho-Saiko-To) commonly administered in Asian countries to outpatients with chronic hepatitis. ${ }^{62}$ Our findings suggest that such compounds may also offer new potential strategies in the pharmacological treatment of $A D$.

\section{Materials and Methods}

\section{Primary neuronal culture}

Rat cortical cultures were prepared from 17-day-old embryonic Wistar rats as described previously. ${ }^{33,63}$ The culture medium consisted of minimum 
essential medium with Earle's salts (Gibco-BRL, Life Technologies, Rockville, MD, USA) supplemented with $5 \%$ fetal calf serum, $2 \mathrm{mM}$ L-glutamine, $5 \mu \mathrm{g} / \mathrm{ml}$ insulin, $2 \times 10^{-8} \mathrm{M}$ progesterone, $100 \mu \mathrm{g} / \mathrm{ml}$ human transferrin $10^{-4} \mathrm{M}$ putrescine, $3 \times 10^{-8} \mathrm{M}$ sodium selenite and $10 \mu \mathrm{g} / \mathrm{ml}$ bovine serum albumin. Cells were seeded in 24-well Costar plates previously coated with poly-D-lysine at a density of $3 \times 10^{5}$ cells per well and grown in a humidified $5 \% \mathrm{CO}_{2} / 95 \%$ air atmosphere at $37^{\circ} \mathrm{C}$.

\section{Treatment of cultures with antisense or sense oligonucleotides}

Oligonucleotides (Invitrogen, Life Technologies, Rockville, MD, USA) used for antisense experiments corresponded to the sequences previously reported to downregulate selectively expression of rat $12-\mathrm{LOX}^{64}$ (antisense: 5'-CTC-AGG-AGG-GTG-TAA-ACA-3'; sense: TGT-TTACAC-CCT-CCT-GAG; scramble: AAG-ATT-GCG-GCG-CGA-CGA-TGA), 5-LOX ${ }^{65}$ (antisense: TCT-GGG-AAG-TGA-GCG-CTG; sense: CAG-CGCTCA-CTT-CCC-AGA) and C-Jun ${ }^{66}$ (antisense: CGT-TTC-CAT-CTT-TGCAGT-CAT; sense: ATG-ACT-GCA-AAG-ATG-GAA-ACG). After 5 days, cultures were treated with the different antisense and sense oligonucleotides at a final concentration of $4 \mu \mathrm{M}$ during $48 \mathrm{~h}$, and then exposed to the $\beta$-amyloid peptide fragment $\mathrm{A} \beta_{25-35}(25 \mu \mathrm{M}$, Alexis Biochemicals, San Diego, CA, USA) for an additional $24 \mathrm{~h}$.

\section{Western blot analysis}

Cells from six wells were washed with phosphate-buffered saline (PBS), and total proteins were extracted by scraping the cells in $100 \mu$ l of protein extracting buffer (10 mM Tris $\mathrm{HCl}, \mathrm{pH} 7.5,150 \mathrm{mM} \mathrm{NaCl}, 0.5 \% \mathrm{NP}-40$ ) containing $0.5 \mathrm{mM}$ EDTA, $1 \mathrm{mM}$ EGTA and phosphatase and protease inhibitors $(0.5 \mathrm{mM}$ sodium orthovanadate, $1 \mu \mathrm{M}$ okadaic acid, $1 \mu \mathrm{g} / \mathrm{ml} \mathrm{N}$ tosyl-L-phenylalanine chloromethyl ketone, $1 \mu \mathrm{g} / \mathrm{ml} N \alpha$-p-tosyl-L-lysine chloromethyl ketone, $20 \mathrm{mM}$ sodium fluoride, $1 \mu \mathrm{M}$ phenylmethylsulfonyl fluoride, $10 \mu \mathrm{g} / \mathrm{ml}$ leupeptin, $10 \mu \mathrm{g} / \mathrm{ml}$ aprotinin and $5 \mu \mathrm{g} / \mathrm{ml}$ pepstatin). Lysates were then sonicated and centrifuged, the resulting supernatants were collected and protein concentrations were determined by BCA assay (Pierce, CA, USA). Samples were mixed with $2 \times$ Laemmli sample buffer and heated at $90^{\circ} \mathrm{C}$ for $5 \mathrm{~min}$. Proteins ( $25 \mu \mathrm{g} / \mathrm{lane}$ ) were separated by electrophoresis on 4-20\% SDS-polyacrylamide gel gradients, transferred to PVDF membranes (Millipore, USA) and probed with either polyclonal anti-12-LOX antibody (1:2000; Cayman Biochemical, Ann Arbor, MI, USA), monoclonal anti-5-LOX antibody (1:250; Transduction Laboratories, Lexington, KI, USA) or polyclonal anti-c-Jun antibody (1:1000; Santa Cruz Biotechnology, Santa Cruz, CA, USA). After incubation with horseradish peroxidase-conjugated anti-rabbit or anti-mouse antibody (DAKO, Denmark), immunoblots were developed using enhanced chemiluminescence (Amersham Bioscience, Orsay, France), stripped and reblotted with an anti-actin antibody (1:4000; Sigma, St. Louis, MO, USA). The densitometric analysis of immunoblot was carried out using ImageQuant software (Molecular Dynamics, Amersham Bioscience, Orsay, France). The 12-LOX 5-LOX and c-Jun immunoreactivities were normalized to actin immunoreactivity.

\section{Treatment of cultures with 12(S)-HETE or 5(S)-HETE}

12(S)-and 5(S)-HETE were purchased from Cayman Biochemical, Ann Arbor, MI, USA. Rat cortical cells grown for 5 days were treated with increasing concentrations $(10 \mathrm{nM}-1 \mu \mathrm{M})$ of $12(S)$ - or $5(S)$-HETE for $24 \mathrm{~h}$ and then subjected to DAPI staining for quantification of apoptotic cells.

\section{Quantification of apoptosis}

To detect morphological evidence of apoptosis, cell nuclei were visualized following DNA staining with the fluorescent dye DAPI (Sigma, St. Louis, MO, USA). Cells were rinsed with PBS, fixed for 20 min in formalin (Sigma, St. Louis, MO, USA), rinsed with PBS and then incubated for 10 min with DAPI $(1 \mu \mathrm{g} / \mathrm{ml}$ PBS). After washing with PBS, cultures were examined using fluorescence microscopy (Microphot FX, Nikon France, Champignysur-Marne, France), and the percentage of apoptotic nuclei with condensed or fragmented chromatin was evaluated.

Detection of apoptosis was also evaluated through TUNEL labeling using the in situ Death Detection Kit POD (Roche Applied Science, Mannheim, Germany). Following DAPI staining, cells were subjected to TUNEL labeling according to the instructions of the manufacturer.

\section{c-Jun immunocytochemistry}

After fixation, cultures were rinsed with PBS and sequentially incubated with $3 \% \mathrm{H}_{2} \mathrm{O}_{2}$ in $\mathrm{PBS}$ for 10 min to inhibit endogenous peroxidase, $10 \%$ horse serum (HS) for $30 \mathrm{~min}$ to saturate aspecific sites, anti-c-Jun primary antibody (Sigma, St. Louis, MO, USA) $1 / 300$ in $1 \%$ HS for $1 \mathrm{~h}$ at $37^{\circ} \mathrm{C}$, biotinylated anti-rabbit secondary antibody (Vector Laboratories, Burlingame, CA, USA) for $1 \mathrm{~h}, \mathrm{ABC}$ solution (Vector Laboratories, Burlingame, $\mathrm{CA}, \mathrm{USA})$ in $1 \% \mathrm{HS}$ for $1 \mathrm{~h}$, rinsed rapidly in $0.1 \mathrm{M}$ Tris-HCl buffer $(\mathrm{pH} 7.4)$ and incubated with $0.05 \%$ diaminobenzidine (Sigma, St. Louis, MO, USA) and $0.01 \% \mathrm{H}_{2} \mathrm{O}_{2}$ in $0.1 \mathrm{M}$ Tris- $\mathrm{HCl}$ for $15 \mathrm{~min}$. The percentage of C-Junpositive neurons was evaluated after nuclear staining with DAPI.

\section{Caspase assay}

Caspase activities were assayed using AMC (7-amino-4-methylcoumarin)related fluorogenic substrates (Alexis Biochemicals, San Diego, CA, USA): Ac-VDVAD-AMC for caspase-2, Ac-DEVD-AMC for caspase-3 and AcIEPD-AMC for caspase-8. Cortical neurons were harvested following a 24$\mathrm{h}$ treatment with $25 \mu \mathrm{M} \mathrm{A} \beta_{25-35}$. To measure caspase activity, cells were washed once with ice-cold PBS, and $250 \mu \mathrm{l}$ ice-cold extraction buffer was added directly to the cultures. The extraction buffer consisted of $50 \mathrm{mM}$ HEPES, 0.1 mM EDTA, $1 \mathrm{mM}$ dithiothreitol, 0.1\% CHAPS, 0.1\% Triton X$100,0.5 \mathrm{mM}$ PMSF and $1 \mu \mathrm{g} / \mu \mathrm{l}$ pepstatin and aprotinin. After $15 \mathrm{~min}$ incubation on ice, the extraction buffer was removed, sonicated, centrifuged for $5 \mathrm{~min}$ at $17000 \times \mathrm{g}$ at $4^{\circ} \mathrm{C}$ and $100 \mu$ of supernatant was added to each well of a 96-well plate. Then, $100 \mu \mathrm{l}$ of $20 \mu \mathrm{M}$ fluorogenic substrate were added to each well to give a final substrate concentration of $10 \mu \mathrm{M}$. Plates were incubated at $37^{\circ} \mathrm{C}$ and cleavage of the fluorogenic substrate was measured over $2 \mathrm{~h}$ with a Spectrafluor fluorometer (TECAN France, Trappes, France) (excitation wavelength: $365 \mathrm{~nm}$; emission wavelength: $460 \mathrm{~nm})$. Protein concentration was determined by the Biorad Protein Assay (Bio-Rad Laboratories, München, Germany).

\section{Statistical analysis}

All experiments were performed at least three times. All values are presented as means \pm S.E.M. Statistical analysis of data was carried out using ANOVA variance analysis followed by Dunnett's or Newman-Keuls tests, using Instat software (GraphPad, San Diego, CA, USA). Differences at $P<0.05$ were considered as significant. 


\section{Acknowledgements}

This work was supported by Institut de la Santé et de la Recherche Médicale (INSERM). A Lebeau was supported by grants from Fondation pour la Recherche Médicale (FRM) and Association France-Alzheimer. We acknowldege L. Victor-Raphael and R. Rambur for technical help and artwork.

\section{References}

1. Bamberger ME and Landreth GE (2002) Inflammation, apoptosis, and Alzheimer's disease. Neuroscientist 8: 276-283

2. Cook JA, Geisel J, Halushka PV and Reines HD (1993) Prostaglandins, thromboxanes, leukotrienes, and cytochrome $P-450$ metabolites of arachidonic acid. New Horiz. 1: 60-69

3. Zandi PP and Breitner JC (2001) Do NSAIDs prevent Alzheimer's disease? And, if so, why? The epidemiological evidence. Neurobiol. Aging 22: 811-817

4. Small DH and McLean CA (1999) Alzheimer's disease and the amyloid $\beta$ protein: what is the role of amyloid? J. Neurochem. 73: 443-449

5. Butterfield DA, Drake J, Pocernich C and Castegna A (2001) Evidence of oxidative damage in Alzheimer's disease brain: central role for amyloid betapeptide. Trends Mol. Med. 7: 548-554

6. Funato H, Yoshimura M, Kusui K, Tamaoka A, Ishikawa K, Ohkoshi N, Namekata K, Okeda R and Ihara Y (1998) Quantitation of amyloid beta-protein (A beta) in the cortex during aging and in Alzheimer's disease. Am. J. Pathol. 152: $1633-1640$

7. Frautschy SA, Baird A and Cole GM (1991) Effects of injected Alzheimer betaamyloid cores in rat brain. Proc. Natl. Acad. Sci. USA 88: 8362-8366

8. Choi SH, Park CH, Koo JW, Seo JH, Kim HS, Jeong SJ, Lee JH, Kim SS and Suh YH (2001) Memory impairment and cholinergic dysfunction by centrally administered Abeta and carboxyl-terminal fragment of Alzheimer's APP in mice. FASEB J. 15: 1816-1818

9. Forloni G (1996) Neurotoxicity of beta-amyloid and prion peptides. Curr. Opin. Neurol. 9: 492-500

10. Harada J and Sugimoto M (1999) Activation of caspase-3 in beta-amyloidinduced apoptosis of cultured rat cortical neurons. Brain Res. 842: 311-323

11. Ivins KJ, Thornton PL, Rohn TT and Cotman CW (1999) Neuronal apoptosis induced by beta-amyloid is mediated by caspase-8. Neurobiol. Dis. 6: 440-449

12. Troy CM, Rabacchi SA, Friedman WJ, Frappier TF, Brown K and Shelanski ML (2000) Caspase-2 mediates neuronal cell death induced by beta-amyloid. J. Neurosci. 20: 1386-1392

13. Allen JW, Eldadah BA, Huang X, Knoblach SM and Faden Al (2001) Multiple caspases are involved in beta-amyloid-induced neuronal apoptosis. J. Neurosci. Res. 65: 45-53

14. Cantarella G, Uberti D, Carsana T, Lombardo G, Bernardini R and Memo M (2003) Neutralization of TRAIL death pathway protects human neuronal cell line from $\beta$-amyloid toxicity. Cell Death Differ. 10: 134-141

15. Dragunow M, Faull RL, Lawlor P, Beilharz EJ, Singleton K, Walker EB and Mee E (1995) In situ evidence for DNA fragmentation in Huntington's disease striatum and Alzheimer's disease temporal lobes. Neuroreport 6: 1053-1057

16. Roth KA (2001) Caspases, apoptosis, and Alzheimer disease: causation, correlation, and confusion. J. Neuropathol. Exp. Neurol. 60: 829-838

17. Kihiko ME, Tucker HM, Rydel RE and Estus S (1999) C-Jun contributes to amyloid beta-induced neuronal apoptosis but is not necessary for amyloid betainduced c-jun induction. J. Neurochem. 73: 2609-2612

18. Morishima Y, Gotoh Y, Zieg J, Barrett T, Takano H, Flavell R, Davis RJ, Shirasaki $Y$ and Greenberg ME (2001) Beta-amyloid induces neuronal apoptosis via a mechanism that involves the c-Jun $\mathrm{N}$-terminal kinase pathway and the induction of Fas ligand. J. Neurosci. 21: 7551-7560

19. Troy CM, Rabacchi SA, Xu Z, Maroney AC, Connors TJ, Shelanski ML and Greene LA (2001) Amyloid-induced neuronal apoptosis requires c-Jun $\mathrm{N}$-terminal kinase activation. J. Neurochem. 77: 157-164

20. Ferrer I, Segui J and Planas AM (1996) Amyloid deposition is associated with c-Jun expression in Alzheimer's disease and amyloid angiopathy. Neuropathol. Appl. Neurobiol. 22: 521-526

21. Shimizu T and Wolfe LS (1990) Arachidonic cascade and signal transduction. J. Neurochem. 55: 1-15
22. Piomelli $D$ and Greengard $P$ (1990) Lipoxygenase metabolites of arachidonic acid in neuronal transmembrane signalling. Trends Pharmacol. Sci. 11:367-373

23. Li Y, Maher P and Schubert D (1997) A role for 12-lipoxygenase in nerve cell death caused by glutathione depletion. Neuron 19: 453-463

24. Maccarone M, Salucci ML, Melino G, Rosato N and Finazzi-Agro A (1999) The early phase of apoptosis in human neuroblastoma CHP100 cells is characterized by lipoxygenase-dependent ultraweak light emission. Biochem. Biophys. Res. Commun. 265: 758-762

25. Maccarone M, Melino G and Finazzi-Agro A (2001) Lipoxygenases and their involvement in programmed cell death. Cell Death Differ. 8: 776-784

26. Tang DG, La E, Kern J and Kehrer JP (2002) Fatty acid oxidation and signaling in apoptosis. Biol. Chem. 383: 425-442

27. Uz T, Pesold C, Longone P and Manev H (1998) Aging-associated upregulation of neuronal 5-lipoxygenase expression: putative role in neuronal vulnerability. FASEB J. 12: 439-449

28. Stewart LR, White AR, Jobling MF, Needham BE, Maher F, Thyer J, Beyreuther K, Masters CL, Collins SJ and Cappai R (2001) Involvement of the 5lipoxygenase pathway in the neurotoxicity of the prion peptide $\operatorname{PrP106-126.~J.~}$ Neurosci. Res. 65: 565-572

29. Muller M, Romero FJ, Perovic S, Pergande G and Pialoglou P (1997) Protection of flupirtine on beta-amyloid-induced apoptosis in neuronal cells in vitro: prevention of amyloid-induced glutathione depletion. J. Neurochem. 68: 2371-2377

30. Bains JS and Shaw CA (1997) Neurodegenerative disorders in humans: the role of glutathione in oxidative stress-mediated neuronal death. Brain Res. Rev. 25: $335-358$

31. Lockhart BP, Benicourt C, Junien JL and Privat A (1994) Inhibitors of free radical formation fail to attenuate direct $\beta$-amyloid ${ }_{25-35}$ peptide-mediated neurotoxicity in rat hippocampal cultures. J. Neurosci. Res. 39: 494-505

32. Goodman Y, Steiner MR, Steiner SM and Mattson MP (1994) Nordihydroguaiaretic acid protects hippocampal neurons against amyloid $\beta$-peptide toxicity, and attenuates free radical and calcium accumulation. Brain Res. 654: 171-176

33. Lebeau $A$, Esclaire $F$, Rostène $W$ and Pélaprat $D$ (2001) Baicalein protects cortical neurons from $\beta$-amyloid (25-35) induced toxicity. Neuroreport 12: 2199-2202

34. Tang DG, Porter AT and Honn KV (1997) Critical role of arachidonate lipoxygenases in regulating apoptosis. Adv. Exp. Med. Biol. 407: 405-411

35. Le Foll I and Duval DP (2000) Programmed cell death induced by glutathione depletion in PC 12 cells is blocked by inhibitors of 12 lipoxygenase, but does not appear to be mediated through the formation of 12 HETE derivatives. Free Radic. Biol. Med. 30: 793-802

36. Ishige $K$, Schubert $D$ and Sagara $Y$ (2001) Flavonoids protect neuronal cells from oxidative stress by three distinct mechanisms. Free Radic. Biol. Med. 30: 435-446

37. Palluy O, Bendani M, Vallat JM and Rigaud M (1994) 12-lipoxygenase mRNA expression by cultured neurons. C. R. Acad. Sci. Paris 317: 813-818

38. Watanabe T, Medina JF, Haeggström JZ, Radmark $O$ and Samuelsson B (1993) Molecular cloning of a 12-lipoxygenase from rat brain. Eur. J. Biochem. 212: 605-612

39. Kamitani H, Ikawa H, Hsi LC, Watanabe T, DuBois RN and Eling TE (1999) Regulation of 12-lipoxygenase in rat intestinal epithelial cells during differentiation and apoptosis induced by sodium butyrate. Arch. Biochem. Biophys. 368: $45-55$

40. Behrens A, Sibilis M and Wagner EF (1999) Amino-terminal phosphorylation of c-Jun regulates stress-induced apoptosis and cellular proliferation. Nat. Genet. 21: $326-329$

41. Ham J, Eilers A, Whitfield J, Neame SJ and Shah B (2000) c-Jun and the transcriptional control of neuronal apoptosis. Biochem. Pharmacol. 60: 1015-1021

42. Nair P, Tammariello SP and Estus S (2000) Ceramide selectively inhibits apoptosis-associated events in NGF-deprived sympathetic neurons. Cell Death Differ. 7: 207-214

43. Estus $\mathrm{S}$, Tucker HM, van Rooyen $\mathrm{C}$, Wright $\mathrm{S}$, Brigham EF, Wogulis $\mathrm{M}$ and Rydel RE (1997) Aggregated amyloid- $\beta$ protein induces cortical neuronal apoptosis and concomitant "apoptotic" pattern of gene induction. J. Neurosci. 17: $7736-7745$

44. Yaar M, Zhai S, Fine RE, Eisenhauer PB, Arble BL, Stewart KB and Gilchrest BA (2002) Amyloid $\beta$ binds trimers as well as monomers of the $75-\mathrm{kDa}$ neurotrophin receptor and activates receptor signaling. J. Biol. Chem. 277: $7720-7725$ 
45. Funk CD (2001) Prostaglandins and leukotrienes: advances in eicosanoid biology. Science 294: 1871-1875

46. Schaad NC, Magistretti PJ and Schorderet M (1991) Prostanoids and their role in cell-cell interactions in the central nervous system. Neurochem. Int. 18: 302-332

47. Nishiyama M, Watanabe T, Ueda N, Tsukamoto $H$ and Watanabe KJ (1993) Arachidonate 12-lipoxygenase is localized in neurons, glial cells, and endothelial cells of the canine brain. Histochem. Cytochem. 41: 111-117

48. Farooqui AA, Yang H, Rosenberg TA and Horrocks LA (1997) Phospholipase $\mathrm{A} 2$ and its role in brain tissue. J. Neurochem. 69: 889-901

49. Foley TD (1997) 5-HPETE is a potent inhibitor of neuronal $\mathrm{Na}+\mathrm{K}+-$ ATPase activity. Biochem. Biophys. Res. Commun. 235: 374-376

50. Freeman EJ, Damron DS, Terrian DM and Dorman RV (1991) 12-lipoxygenase products attenuate the glutamate release and $\mathrm{Ca}^{2+}$ accumulation evoked by depolarization of hippocampal mossy fiber nerve endings. J. Neurochem. 56: 1079-1082

51. Piomelli D, Volterra A, Dale N, Siegelbaum SA, Kandel ER, Schwartz JH and Belardetti F (1987) Lipoxygenase metabolites of arachidonic acid as second messengers for presynaptic inhibition of Aplysia sensory cells. Nature 328: 38-43

52. Carlen PL, Gurevitch N, Wu PH, Su WG, Corey EJ and Pace-Asciak CR (1989) Actions of arachidonic acid and hepoxilin A3 on mammalian hippocampal CA 1 neurons. Brain Res. 497: 171-176

53. Rohn TT, Head E, Su JH, Anderson AJ, Bahr BA, Cotman CW and Cribbs DH (2001) Correlation between caspase activation and neurofibrillary tangle formation in Alzheimer's disease. Am. J. Pathol. 158: 189-198

54. Su JH, Zhao M, Anderson AJ, Srinivasan A and Cotman CW (2001) Activated caspase-3 expression in Alzheimer's and aged control brain: correlation with Alzheimer pathology. Brain Res. 898: 350-357

55. Qu T, Manev R and Manev H (2001) 5-Lipoxygenase (5-LOX) promoter polymorphism in patients with early-onset Alzheimer's disease. J. Neuropsychiatry Clin. Neurosci. 13: 304-305
56. Marcus DL, Strafaci JA, Miller DC, Masia S, Thomas CG, Rosman J, Hussain S and Freedman ML (1998) Quantitative neuronal c-fos and c-jun expression in Alzheimer's disease. Neurobiol. Aging 19: 393-400

57. Sawada H, Ibi M, Kihara T, Urushitani M, Honda K, Nakanishi M, Akaike A and Shimohama S (2000) Mechanisms of antiapoptotic effects of estrogens in nigral dopaminergic neurons. FASEB J. 14: 1202-1214

58. Bozyczko-Coyne D, O'Kane TM, Wu ZL, Dobrzanski P, Murthy S, Vaught JL and Scott RW (2001) CEP-1347/KT-7515, an inhibitor of SAPK/JNK pathway activation, promotes survival and blocks multiple events associated with Abetainduced cortical neuron apoptosis. J. Neurochem. 77: 849-863

59. Ip YT and Davis RJ (1998) Signal transduction by the c-Jun N-terminal kinase (JNK)-from inflammation to development. Curr. Opin. Cell Biol. 10: 205-219

60. Saez-Valero J, Angeretti N and Forloni G (2000) Caspase-3 activation by betaamyloid and prion protein peptides is independent from their neurotoxic effect. Neurosci. Lett. 293: 207-210

61. Troy CM and Shelanski ML (2003) Caspase-2 redux. Cell Death Differ. 10: 101-107

62. Shimizu I, Ma Y-R, Mizobuchi Y, Liu F, Miura T, Nakai Y, Yasuda M, Shiba M, Horie T, Amagaya S, Kawada N, Hori H and Ito S (1999) Effects of Sho-saikoto, a japanese herbal medicine, on hepatic fibrosis in rats. Hepatology 29: 149-160

63. Hugon J, Hugon F, Esclaire F, Lesort M and Diop AG (1996) The presence of calbindin in rat cortical neurons protects in vitro from oxidative stress. Brain Res. 707: 288-292

64. Tang DG, Chen YQ and Honn KV (1996) Arachidonate lipoxygenases as essential regulators of cell survival and apoptosis. Proc. Natl. Acad. Sci. USA 93: $5241-5246$

65. Uz T, Manev R and Manev H (2001) 5-Lipoxygenase is required for proliferation of immature cerebellar granule neurons in vitro. Eur. J. Pharmacol. 418: 15-22

66. Mulderry PK and Dobson SP (1996) Regulation of VIP and other neuropeptides by $c$-jun in sensory neurons: implications for the neuropeptide response to axotomy. Eur. J. Neurosci. 8: 2479-2491 